\title{
On the Thermal History of the Earth $\left(^{*}\right)$
}

\author{
B. J. Levin and S. V. MaJeva (**)
}

Ricevuto il 7 dicembre 1960

The thermal history of the Earth has been investigated during last decade in the Otto Schmidt Institute of Physics of the Earth. In the analogous investigations of other authors (Jacobs and Allan, MacDonald) both the cold and the hot initial state of the Earth were admitted. In our Institute all calculations were based on the theory of the origin and evolution of the Earth developed from Prof. Schmidt's ideas. All calculations were made for the initially cold Earth heated by radioactivity.

At first the thermal history of the uniform Earth model taking into account the previously neglected time-dependence of radioactive heat production was calculated by E. A. Lubimova (1952). It was shown that the mean content of radioactive elements in meteorites is sufficient for the explanation of the present incandescent state of the Earth's interior. In subsequent calculations (Lubimova, 1955-58) the non-uniform distribution of radioactive elements in the Earth at the present time as well as the dependence of heat transport on temperature and pressure were taken into account.

In the present paper the results of some new calculations are discussed. Their main purpose was: $a$ ) to study the thermal history of the outer parts of the Earth assuming a longenduring (not instantaneous) formation of the crust resulting from the differentiation of the mantle, and $b$ ) to compare the calculated heat flows for the continental and oceanic parts of the Earth. We wished also to clarify if it is possible to fit the observed heat flow with the smaller content of radioactive elements in the Earth then adopted in previous calculations.

Our results were already in press when a paper by MacDonald (1959) was published. He had calculated a thermal history for a great series

(*) Paper read at the Helsinky Assembly of the I.U.G.G., 1960. Acad. Sci.

(**) O. J. Schmidt Institute of Physics of the Earth, Moscow, USSR 
of models. But in the time-dependent solutions only the distribution of temperature in the mantle is calculated. The core is supposed to be thermally insulated and the existance of the crust enriched by radioactive elements is not taken into account. Nevertheless MacDonald's paper gives an independent confirmation to some conclusions obtained earlier by Lubimova.

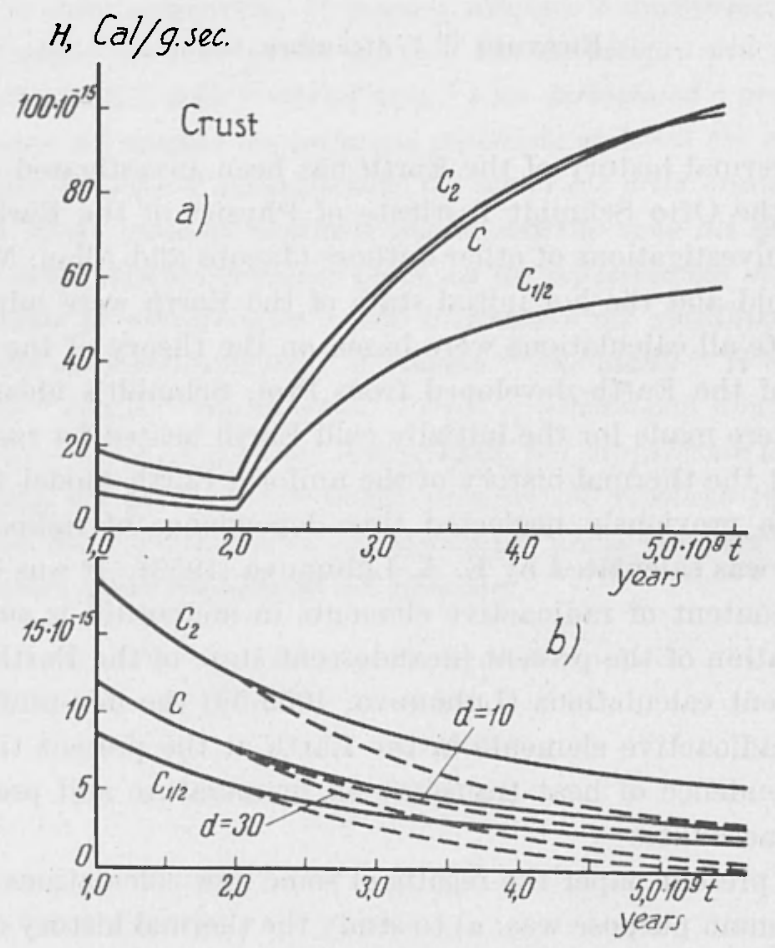

Fig. 1 - Heat output from the crust (a) and from the depleted part of the mantle (b).

- non-depleted part of the mantle and core.

- - - - - - depleted part of the mantle

Our calculations were made for the following Earth's model: For the dense core of the Earth Ramsey's hypothesis is adopted, and therefore the core is supposed to exist from the very beginning of the time interval for which the thermal calculations were made. In accordance with the formation of the Earth by accumulation of cold particles the initial distribution of radioactive elements is adopted to be uniform (per unit of mass) throughout the whole Earth. The Earth began to accumulate $5 \times 10^{\circ}$ 
years ago. From this moment is measured the time $t$ used in the calculations.

The real formation process of the crust was probably the gradual growth of its thickness. For the sake of simplicity of calsulations this was replaced by the gradual growth of the concentration of radioactive elements in the crust of constant thickness. For the continental parts of the Earth the thickness of the crust $d=30 \mathrm{~km}$ was adopted and for the oceanic crust $d=10 \mathrm{~km}$ The concentration of radioactive elements in the crust began to increase at $t=2 \times 10^{9}$ i.e. 3 billions years ago. This occured as a result of the uniform depletion of these elements in the upper part of the mantle down ot the depth of $1000 \mathrm{~km}$. For the crust the following formula for the time-dependence of heat generation was adopted

$$
H(t)=\left(1+k \frac{t-2.1 v^{n}}{3.10^{9}}\right) \Sigma H_{i}(0) e^{-\hat{n}_{i} i}
$$

As previously, the chemical composition of the Earth was supposed to be the same as the true mean composition of the meteoritic matter The mean content of radioactive elements in the meteoritic matter, obtained by $A$. Starkova in 1955 must be seriously corrected because the new analyses of meteorites give as a rule much smaller content of uranium and thorium. Therefore the calculations were made not only for the mean content obtained by Starkova and used in the last paper by Lubimova (variant $C$, see table), but also for the variant $C_{1 / 2}$ in which the potassium content is not changed but the content of uranium and thorium is two times smaller.

$\begin{array}{ccc}\text { Element } & \text { variant } C & \text { variant } C_{1 / 2} \\ \mathrm{U} & 5.2 \cdot 10^{-8} & 2 \cdot 6.10^{-8} \\ \mathrm{Th} & 21 \cdot 10^{-8} & 10 \cdot 5 \cdot 10^{-8} \\ \mathrm{~K} & 0.7 \cdot 10^{-3} & 0 \cdot 7 \cdot 10^{-3}\end{array}$

The results by J. E. Starik and M. Shatz (1956) who obtained a very great content of uranium and thorium in meteorites, inspired us to make some calculations for the variant $C_{2}$ in which the content of $\mathrm{U}$ and $\mathrm{Th}$ is two times greater. But this variant lears to excessively great values of the temperature in the Earth's interior and of the heat flow through the surface.

The present heat generation in the crust was adopted to be equal to the mean generation in 1 part (by volume) of granit and 2 parts of 
basalt. According to the data by Birch (1954) this heat generation is $9,7 \times 10^{-14} \mathrm{cal} / \mathrm{g}$ sec or 30,6 times greater than the generation in the nondifferentiated Earth's matter according to variant $C$. Therefore in formula [1] we obtain $k=29,6$. The present generation of heat in the depleted part of the mantle follows to be $6,3 \times 10^{-16} \mathrm{cal} / \mathrm{g} \mathrm{sec}$, the same as in dunite

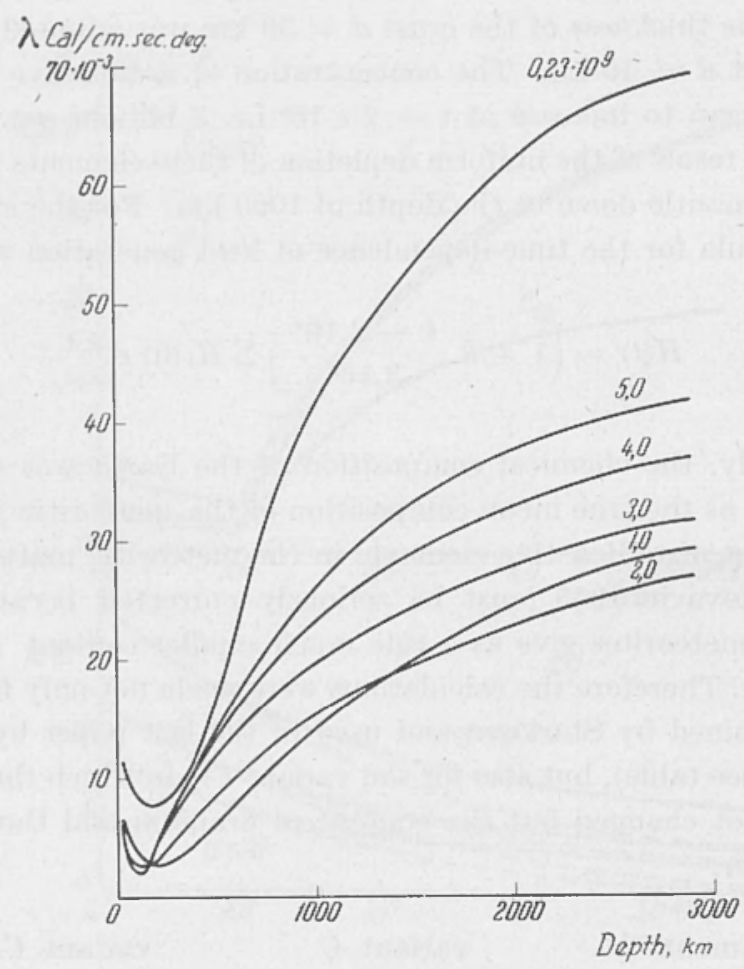

Fig. 2 - Total conductivity versus depth $\lambda(T, p)$. $C, d=30, \varepsilon=200, c=0,2$.

according to Birch. For the variant $C_{1 / 2}$ the same value of $k$ gives the heat generation in the crust to be $6,7 \times 10^{-11}$ and in the depleted part of the mantle $3,5 \times 10^{-16}$. The initial radial distribution of the temperature at the time of the practical end of the Earth's growth was taken according to V. S. Safronov (1959) for the case of the duration of the growth equal to $0,23 \times 10^{9}$ years. The subsequent changes of the temperature (after $t=0,23 \times 10^{9}$ ) were calculated on the hydraulic integrating machine constructed by V. S. Lukyanov (1939). 
In the core the metallic heat conductivity $\lambda-0,5 \mathrm{cal} / \mathrm{cm}$ sec degree independent on temperature and pressure was adopted. In the mantle and crust the lattice and radiative conductivitis were taken into account. The dependance of lattice conductivity on temperature and pressure was taken according to V. N. Zharkov (1958)

$$
\lambda_{m}=\text { const } \frac{f(p)}{T}
$$

where the pressure function $f(p)$ increases 25 times from the surface to the mantle and core boundary. The constant in [2] was evaluated adopting $\lambda=1,2 \times 10^{-2} \mathrm{cal} / \mathrm{cm}$ sec degree (dunite) in the conditions of the Earth's surface.

In the formula for the radiative conductivity

$$
\lambda_{2}=\frac{16}{\jmath} \frac{\sigma n^{2}}{\varepsilon} T^{3}
$$

the absorption coefficient $\varepsilon$ in the most part of calculations was taken equal to $200 \mathrm{~cm}^{-1}$ and in some calculations $40 \mathrm{~cm}^{-1}$. Our results would remain valid also if it were shown that not the radiative conductivity but the exciton conductivity is of importance in the Earth's interior. An example of the change of the total conductivity with the depth is shown on fig. 2 .

The heat capacity was taken $c=0,2 \mathrm{cal} / \mathrm{g}$ and in some cases $c=0,3$ According to Jacobs (1956) the heat capacity of the mantle is within these limits. It must be the same also for the core if the latter has the same composition according to Ramsey's hypothesis adopted by us.

The general character of the radial distribution of temperature for different moments of time can be seen on fig. 3 (the variant $C$ of the content of radioactive elements; heat capacity $c=0,2$ and $0,3 \mathrm{cal} / \mathrm{g}$ ). The knick of the curves at the mantle-core boundary arises because the total heat conductivity of the mantle, even if the radiatice conductivity is taken into account, remains smaller than the metallic conductivity of the core.

The outflow of heat from the core is small and therefore with $c=0,2$ the central temperature is about 1,5 times greater than with $c=0,3$. For the variant $C$ the present central temperature is contained within $4400-6500^{\circ} \mathrm{K}$ and for the variant $C_{1 / 2}$ - within $3000-4500^{\circ} \mathrm{K}$. For the greater role of radiative conductivity $\left(\varepsilon=40 \mathrm{~cm}^{-1}\right)$ the depth of outer zone from which the heat flows out is also greater and it reaches the 
boundary of the core. Therefore the temperature of the core comes to be about $100^{\circ}$ lower than for $\varepsilon=200$.

The comparison of temperatures calculated for the present moment of time with the melting temperatures is given on fig. 4. For the mantle the melting curves according to Uffen (1952) and to V.N. Zharkov are given, and for the core - the melting curve for iron according to Zharkov (1959). (According to data by Strong the melting temperatures of iron are substantially lower). For the variant $C$ of the content of radioactive elements if $c=0,2$ the temperature curve for the present time passes over the melting curves. Probably this does not correspond to the real

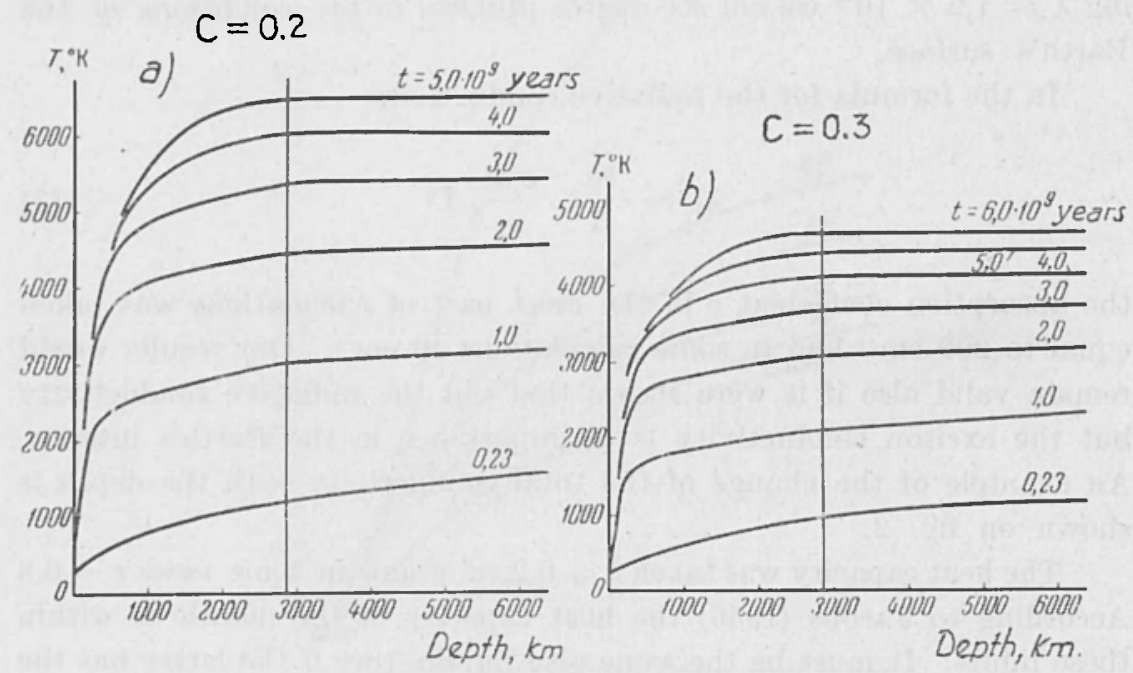

Fig. 3 - Temperature variation with depth.

situation. For $c=0,3$ the temperature distribution is almost the same as for variant $C_{1 / 2}$ and $c=0,2$. Remembering the uncertainty of the melting curves we can say that this distribution of temperature (or a similar one passing somewhat lower) agrees with the concept of the partial melting of the mantle which began about 3 billion years ago. In order to obtain the solid inner core and the fluid outer part of it we must suppose that the matter of the core being in metallic state has melting temperature intermediate between Zharkov's ans Strong's data for the iron.

MacDonald has made all his calculations for the minimal values of uranium and thorium content, obtained in recent analyses of meteorties by the neutron-activation method $\left(U-1,1 \times 10^{-8} ; T h-4,4 \times 10^{-8}\right)$. 
In this case the generation of heat is so small that the melting of the outer parts of the mantle occures only for the present time and only if the high initial temperature of the Earth is supposed. But in the real Earth the partial melting of the mantle was the cause of the formation of the crust which began about 3 billion years ago. Moreover the great initial temperature of the Earth can be due to the shortlived isotopes only and this requires the formation of the Earth from the matter which had shoitly vefore passed the process of nucleogenesis. Very small uranium and thorium contents adopted by MacDonald can lead also to dif-

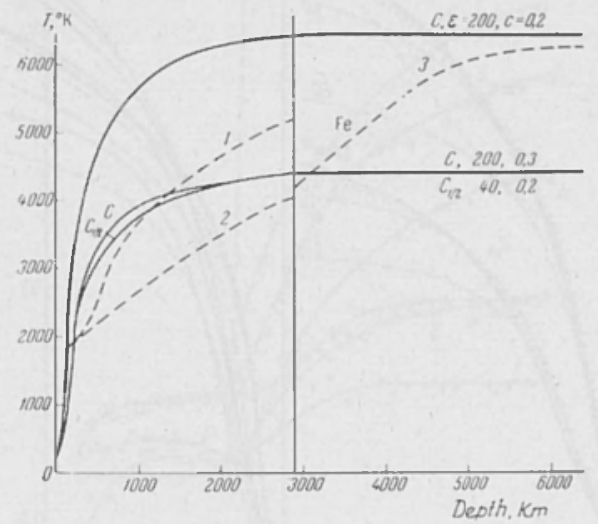

Fig. 4 - Temperatures calculated for the present moment of time as compared to the melting temperatures. 1 - after R. Uffen (1952). $2,3-$ V. N. Zharkov (1959).

ficulties in explaining the observed heat fiow. MacDonald agrees that the lattice conductivity decreeses with temperature (see form [2]) but in his calculations he puts it to be constant. He does not take into account the low-conductivity layer at the depth $100-200 \mathrm{~km}$ (see fig. 2) and therefore he overestimates the heat flow through the surface.

When the longenduring character of the redistribution of radioactive elements is taken into account, falls off the substantial cooling of outer layers obtained by Lubimova for the case of instantaneous redistribution. In the variant $C$ for the continental part of the Earth (thickness of the crust $d=30 \mathrm{~km}$ ) we obtained some cooling at the depth of 200-600 $\mathrm{km}$ which does not exceed $200^{\circ}$ and for the oceanic part $(d=10 \mathrm{~km}$ ) there is no cooling at all (see fig. 5). For the variant $C_{i_{i 2}}$ the result is analogous. 
At the same time - and that is very important — we obtained for all variants that the temperature at the crust-mantle boundary continues to increase. It is due to the increase of the generation of heat in the crust because with the adopted linear law of concentration of radioactive elements into the crust their income from the mantle overcompensates their decay (see fig. 1).

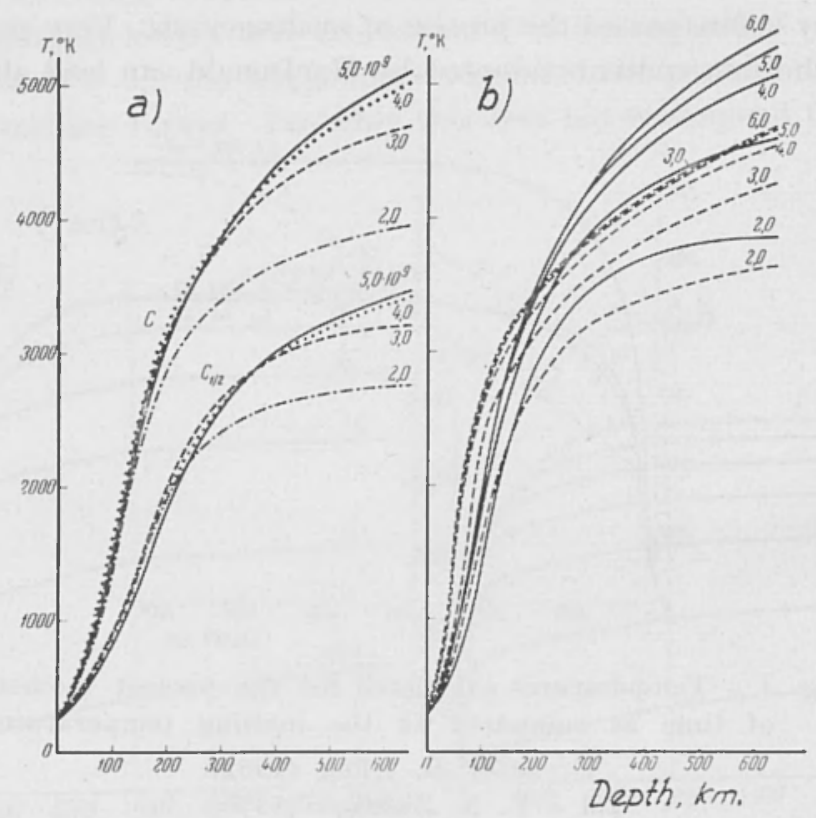

Fig. 5 - Temperature distribution in the upper layers of the Earth.

a) continental part of the Earth

b) oceanic part of the Earth.

$------\varepsilon=40$. $\varepsilon=200$.

The temperature changes in the lower part of the crust are directly connected with the changes of the heat flow through the Earth's surface (fig. 6). The almost constant flow was reached at the end of the stage of uniform distribution of radioactive elements (for the uniform model it would begin to decrease) and after the beginning of the redistribution it began to increase again and this increase continues till now. In the case of instantaneous formation of the crust there would be a sharp increase of heat flow followed by a decrease. 
For both variants of content of radioactive elements $\left(C\right.$ and $\left.C_{1 / 2}\right)$ all calculations give the present heat flow which is in accordance with the observed one within the uncertainity of the latter. For the case of a thin

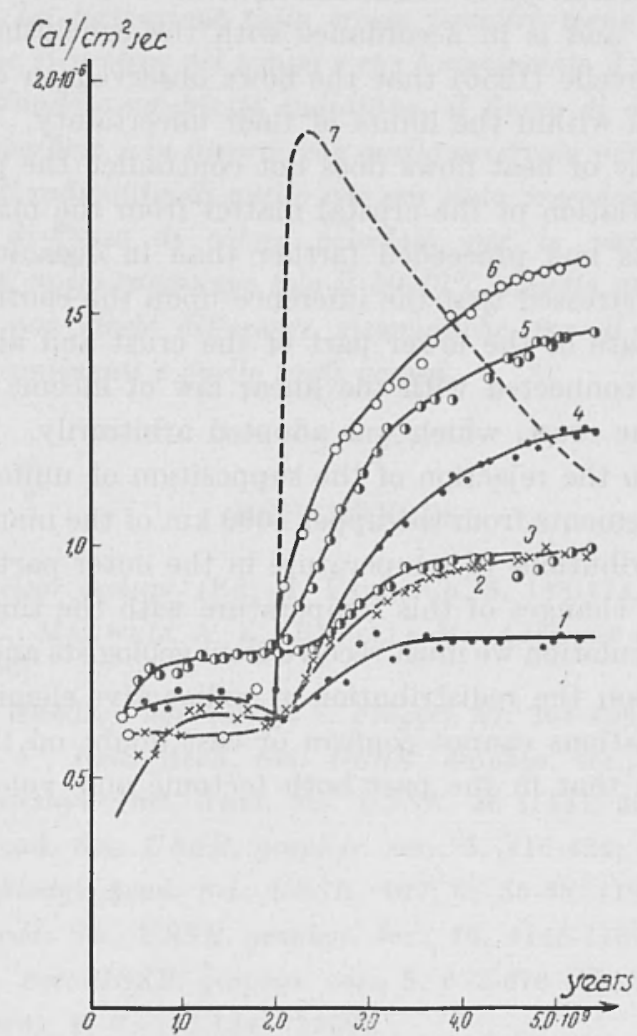

Fig. 6 - Superficial heat flow variation with the time.

$\begin{array}{llrr}1-\mathrm{C}, d=20, \quad \varepsilon=200, & c=0,3 \\ 2-\mathrm{C}, & 10, & 200, & 0,2 \\ 3-\mathrm{C} 1 / 9 & 30, & 40, & 0,2 \\ 4-\mathrm{C}, & 30, & 200, & 0,3 \\ 5-\mathrm{C}, & 30, & 200, & 0,2 \\ 6-\mathrm{C}, & 10, & 40, & 0,2 \\ 7-\mathrm{C}, & 30, & 200, & 0,2\end{array}$

(Curve 7 corresponces to the instantanoeus formation of the crust)

oceanic crust the heat flow is of course smaller than for the case of a thicker continental crust. But the heat flow originates not only in the crust but also inflows from the mantle and therefore the difference of 
calculated heat flows is much less than the difference in thickness between the continental and oceanic crust. The increase of the role of radiative conductivity decreases the difference of heat flows But even if the role of radiative conductivity is small, this difference in heat flows amounts only to $30-40 \%$ and is in accordance with the conclusion by Bullard, Naxwell and Revelle (1956) that the flows observed on continents and oceans are equal within the limits of their uncertainty. Therefore this observed equality of heat flows does not contradict the concept of the gradual differentiation of the crustal matter from the mantle, which in continental parts had proceeded farther than in oceanic ones.

It must be stressed that the inference upon the continuing increase of the temperature of the lower part of the crust and also of the heat flow is directly connected with the linear law of income of radioactive elements into the crust, which was adopted arbitrarily. The change of this law and also the rejection of the supposition of uniform extraction of radioactive elements from the upper $1000 \mathrm{~km}$ of the mantle would lead to different distributions of temperature in the outer parts of the Earth and to different changes of this temperature with the time.

For this calculation we must receive from geologists and geophysicists reliable data upon the redistribution of radioactive elements. Without them our calculations cannot confirm or cast doubt on the supposition of some authors that in the past both tectonic and volcanic activities were greater.

\section{$S U M M A R Y$}

The thermal history is calculated for several models of the initially cold Earth. The formation of the Earth's crust is regarded as a longenduring process, which started $3 \times 10^{\ominus}$ years ago. In the case of great radiative conductivity the calculated heat flow through the surface is in agreement with the observed one for smaller content of radioactive elements than it was admitted earlier. The difference of heat flows calculated for the continental and oceanic parts of the crust amounts only 30-40\%. This can explain why the observation does not reveal systematic differences between heat flows on continents and on oceans. 


\section{RIASSUNTO}

La storia termica viene calcolata per vari modelli della terra inizialmente fredda. La formazione della crosta terrestre viene considerata come un processo che si protrae nel tempo e che e cominciato $3 \times 10^{9}$ anni or sono. $\mathrm{Nel}$ caso di grande conduttivita radiattiva, il flusso di calore calcolato attraverso la superficie e in accordo con quello osservato per un contenuto minore di elementi radioattivi di quello che era stato precedentemente ammesso. La differenza di flusso di calore calcolato per le parti continentali $e$ oceaniche della crosta raggiunge solo il 30-40\%. Questo pù̀ spiegare perche l'osservazione non rivela differenze sistematiche tra il flusso di calore registrato nei continenti e quello negli oceani.

\section{REFERENCES}

Birch F., Nuclear geology. (Ed. H. Faul), Ch. 5, 148-174, (1954).

Bullard E. C., Maxwell A. E., Revelle R., Advances in geophysics, 153 $181,(1956)$.

JACOBS J. A., Handb. Phys. (Hrsg. S. Flügge), 47, 364-406, (1956).

Lubimova E. A., Bull. Acad. Sci. USSR, geophys. ser., 2-3, 14, (1952).

- a) Publ. Geophys. Inst. Acad. Sci. USSR, 26 (153), 39-50, (1955).

— b) Bull. Acad. Sci. USSR, geophys. ser., 5, 416-424, (1955).

- a) $C R$ (Doklady) Acad. Sci. USSR, 107, 1, 55.58, (1956).

- b) Bull. Acad. Sci. USSR, geophys. ser., 10, 1145-1160, (1956).

- Bull. Acad. Sci. USSR, geophys. ser., 5, 673-676 (1957).

- Geoph. Journ., 1, 2, 115-134, (1958).

Lukyanov V. S., Bull. Acad. Sci. URSS, Otdeleniye Technich. Nauk, 2, 53-67, (1939).

MacDonald G., Journ. Geophys. Res. 64, 11, 1967-2000, (1959).

Safronov V. S., Bull. Acad. Sci. USSR, geophys. ser., 1, 139-143, (1959).

StaRIK J. E. and Shatz M. M., Geochemistry (USSR), 2, 19-26, (1956).

Starkova A.'G., Meteoritics (USSR), 13, 19-32, (1955).

UFFEN R., Trans. Am. Geoph. Un., 33, 6, 893-896, (1952).

Zharkov V. N., Bull. Acad. Sci. USSR, geophys. ser., 11, 1342-1350 (1958).

— Bull. Acad. Sci. USSR, geophys. ser., 3, 465-470, (1959). 